\title{
Reduced Drinking in Alcohol Dependence Treatment, What Is the Evidence?
}

\author{
Karl Mann ${ }^{a}$ Henri-Jean Aubin ${ }^{b, c}$ Katie Witkiewitz ${ }^{d}$ \\ ${ }^{a}$ Central Institute of Mental Health, Medical Faculty Mannheim, University of Heidelberg, Mannheim, Germany; \\ bUniversité Paris-Saclay, Universitaires Paris-Sud, and CAPHP, Hôpitaux Universitaires Paris-Sud, Site Paul Brousse,

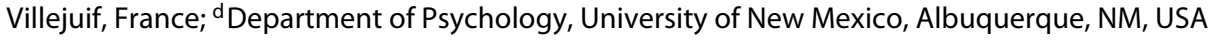

\section{Keywords}

Alcohol dependence $\cdot$ Harm reduction · Reduced drinking · Pharmacotherapy · Controlled drinking

\begin{abstract}
Abstinence from alcohol has been the prevailing treatment goal for individuals with alcohol dependence (AD) within the context of specialty alcohol treatment. Yet, alcohol use has been conceptualized as existing on a continuum. Importantly, most people who meet criteria for AD and could benefit from treatment never receive treatment. About half of these individuals do not seek treatment because they report a desire to continue drinking. To increase acceptability of treatment, reductions in alcohol consumption have been examined as alternative outcomes in treatment trials for AD. The current study reviews data which indicate that long-term reduction in alcohol consumption among patients with AD is possible. Controlled studies have tested reduced alcohol consumption and show sustained improvements in drinking reductions for many patients following behavioral treatments and pharmacotherapy. Evidence-based treatment guidelines and medicines development guidance authorities have taken note of these developments and accept "intermediate harm reduction" (European Medicines Agency)
\end{abstract}

or "low-risk drinking limits" (US Federal Drug Administration) as optional trial endpoints. In conclusion, while abstinence remains the safest treatment goal for individuals with $A D$, evidence supports that reduced drinking approaches may be an important extension in the treatment of AD.

(c) 2017 S. Karger AG, Basel

\section{Introduction}

In 2010, the European Medicines Agency (EMA) published a guidance paper for the development of medicinal products for treating patients with alcohol dependence (AD) [1]. While abstinence is the prevailing treatment goal, it also allows for an "intermediate harm reduction strategy." Establishing efficacy based on such an intermediate harm reduction strategy requires a clinically significant reduction in total alcohol consumption, as well as a clinically significant reduction in the number of heavy drinking days (with heavy drinking days defined as $60 \mathrm{~g}$ of pure alcohol in men and $40 \mathrm{~g}$ in women). In addition, the EMA considered evaluating the proportion of subjects with a "significant categorical shift" (p. 10) in World Health Organization (WHO) [2] risk levels of drinking (Table 1). The EMA argues that reducing drinking by at

\section{KARGER}

(c) 2017 S. Karger AG, Basel 
Table 1. World Health Organization drinking risk levels

\begin{tabular}{lcc}
\hline & Males, g/day & Females, g/day \\
\hline Risk levels of drinking & & \\
Low risk & $1-40$ & $1-20$ \\
Medium risk & $41-60$ & $21-40$ \\
High risk & $61-100$ & $41-60$ \\
Very high risk & $101+$ & $61+$ \\
\hline Criteria for risk of consumption on a single drinking day in \\
relation to acute problems ${ }^{1}$, g/day & \\
Low risk & $1-40$ & $1-20$ \\
Medium risk & $41-60$ & $21-40$ \\
High risk & $61+$ & $41+$ \\
\hline
\end{tabular}

Criteria for risk of chronic harm [1].

Criteria proposed by the European Medicines Agency for risk levels of drinking [1], after [2].

According to the European Medicines Agency, the most acceptable level of consumption (apart from abstinence) concerning health outcome both at short- and long-term use is the low risk level (1-40 $\mathrm{g}$ of pure alcohol on a single drinking day for men and 1-20 $\mathrm{g}$ of women). Of note for really everyday consumption, WHO recommends currently a limit of $7 \mathrm{~g}$ pure alcohol and even this is considered too much for some special groups, such as pregnant women or patients with liver cirrhosis [1].

least 2 categories bears positive consequences for the individual and can thus be used as a viable secondary endpoint for clinical trials.

The EMA guidance paper and other recent reviews [3, 4] have kindled a renewed interest in an old question: can patients with $\mathrm{AD}$ who suffer from impaired control over alcohol intake regain less risky consumption for extended periods of time? In the current study, we shall briefly refer to the old debate on "controlled drinking" and provide an update on new evidence since the publication of recent reviews on the topic. This comprises studies comparing abstinence and reduced consumption goals and on the natural history of alcohol use disorders. Since, to date, only few controlled trials prospectively looked at the effect of reduced alcohol consumption, we shall also include other sources and allude to studies whose results indirectly support or refute the value of reduced consumption.

\section{Alcohol-Derived Harm and Harm Reduction in AD}

Alcohol use contributes considerably to mortality [5, 6]. Most risk curves relating disease and injury outcomes to average alcohol intake show a monotonic dose-response, where higher alcohol consumption is related to a higher risk of mortality. The most common shape of these risk curves is exponential [7]. There are, however, some exceptions, particularly for cardiovascular ischemic conditions [8] and diabetes [9], where the curve shows a J-shape and mortality risk is decreased with a low level of alcohol consumption, as compared to abstinence. Recent findings suggest that the J-shaped curve might not be applicable to ethnic and racial minorities [10] and meta-analyses show an exponential allcause mortality increase after an average consumption of $10 \mathrm{~g}$ per day [11]. This debate is still ongoing with new analyses better adjusting for confounders [12-14] challenging the existence of a J-shaped relationship between alcohol consumption and all-cause mortality. Yet, it is important to note that even in the absence of a J-shaped curve the dose-response relationship has held across studies [15-17], thus higher alcohol consumption is related to higher risk of mortality and reductions in alcohol consumption are associated with a reduced risk of mortality [18] and improvements in physical and mental health [19].

Harm reduction has been defined as a "pragmatic approach to reduce the harmful consequences of drug use and other high-risk activities by incorporating several strategies that cut across the spectrum from safer use to managed use to abstinence" [20]. As a public health approach, harm reduction accepts alternatives to abstinence, including reductions in drinking as a useful and important treatment target [21]. The concept of harm reduction introduced for individuals with heroin addiction several decades ago was primarily concerned with directly targeting drug harms without necessarily reducing consumption itself [22]. In patients with $\mathrm{AD}$, where abstinence is not achievable or not accepted by the individual, it has been postulated that harm reduction in terms of reduced alcohol consumption could improve the wellbeing and functioning [23].

Brief interventions which are widely used, especially in early stages of alcohol use disorders, are an example of an established harm reduction approach. Here a reduction of consumption from heavy drinking to moderate levels of drinking is the usual goal and abstinence is rare [24]. Typically, brief interventions are used for individuals with less severe $\mathrm{AD}[25]$ and only recently has it been proposed that harm reduction approaches may also be appropriate for more severely affected clinical populations of patients with $\mathrm{AD}$ who are seeking specialty $\mathrm{AD}$ treatment or alcohol medications [4]. Such a pragmatic definition of outcomes is common in other fields of psychiatry, such as depression or schizophrenia. They do not require or expect a complete absence of any depression or psy- 
chotic symptoms. For example, a 50\% reduction in depression ratings is accepted as an indicator of treatment success [26].

\section{Treatment Gap in $A D$}

One important stimulus to introduce a harm reduction approach to $\mathrm{AD}$ is that only a few people have been seeking treatment for $\mathrm{AD}$. The so-called treatment gap pointed out in a review of epidemiology studies distinguishing $3 \mathrm{WHO}$ world regions (Europe, US, Western Pacific; Table 2) [27], as well as in an analysis of the US National Epidemiological Study on Alcohol and Related Conditions (NESARC) survey [28] is a major problem: in Europe, AD treatment reaches only $10-15 \%$ [29] of the population in need (the treatment gap is approximately $85-90 \%$ ), whereas the treatment gap is only $56 \%$ for affective disorders and 32\% for schizophrenia [27]. When individuals who meet criteria for AD are asked why they do not want to receive treatment for an alcohol problem, surveys have found nearly half of all individuals with $\mathrm{AD}$ not seeking treatment because they do not want to give up drinking completely [30,31]. Other research has suggested that the majority of people with DSM-5 AUD who do not seek treatment are less severe and, thus, these individuals do not consider taking treatment [32].

Given the large number of afflicted people, we therefore need to refine and extend treatment options for alcohol use disorders. While there is little hope for magic medication or perfect psychotherapies, 2 avenues hold promise: (i) personalized (precision) medicine $[33,34]$ and (ii) a harm reduction strategy, which accepts treatment goals below the high bar of abstinence [1]. In this study, we extend the prior review of van Amsterdam and van den Brink [4] by focusing on new data concerning the concept of harm reduction for $\mathrm{AD}$ whereby reductions in alcohol consumption are assumed to confer less harm, even if total abstinence is not achieved $[20,35,36]$.

\section{Examining Reduced Alcohol Consumption in Treatment Trials and Population-Based Studies}

A number of small sample longitudinal studies have found that individuals often reduce their alcohol use over time in the absence of treatment $[37,38]$. Even among those who receive treatment, many individuals with $\mathrm{AD}$ are able to achieve "low level," "social," and "normal" levels of drinking (with exact amounts of drinking defined differently across studies) [39-42]. The US Project
Table 2. The treatment gap in mental health [27]

\begin{tabular}{llll}
\hline & \multicolumn{3}{l}{$\begin{array}{l}\text { Percentage of patients not } \\
\text { receiving treatment }\end{array}$} \\
\cline { 2 - 4 } WHO region & $\begin{array}{l}\text { Europe, } \\
\%\end{array}$ & $\begin{array}{c}\text { USA, } \\
(\%)\end{array}$ & $\begin{array}{l}\text { Western } \\
\text { Pacific, (\%) }\end{array}$ \\
\hline Schizophrenia & 18 & 57 & 36 \\
Bipolar disorder & 40 & 60 & 53 \\
Major depression & 45 & 57 & 48 \\
Panic disorder & 47 & 55 & 67 \\
Generalized anxiety & 62 & 50 & 56 \\
Alcohol abuse/dependence & 92 & 73 & 72 \\
\hline
\end{tabular}

MATCH $(n=1,726)$ compared 3 forms of psychotherapy, cognitive-behavioral treatment, motivation enhancement treatment, and 12-step facilitation treatment, in patients with AD. All 3 arms led to clear improvement in a number of domains. While the Project MATCH required an abstinence goal, secondary analyses of the Project MATCH data [43] identified many patients who were drinking moderately (defined as less than 5 standard drinks per occasion for men and less than 4 standard drinks per occasion for women) at the follow-up assessments, with between 10\% (6 months) and 20\% (12 months) of patients reporting moderate consumption in the 30 days prior to the assessment. Patients classified as moderate drinkers at the end of the first year had intermediate 3-year outcomes between results of abstainers and heavy drinkers [43]. However, other analyses found that the likelihood of maintaining moderate drinking was lower in severely dependent patients (more than 6 dependence criteria out of 9 [DSM-IIIR]) [44], which is consistent with several other studies showing that moderate drinking goals might be most appropriate for individuals with lower levels of AD severity [45-47]. Similarly, a recent secondary analysis of the COMBINE study data showed stability of no heavy drinking as an outcome within the first 4 months of treatment [48].

In the USA, the large general population NESARC study investigated transitions in and out of alcohol-dependence in individuals without offering treatment. Prior to wave $1(2001 / 2002), 4,422$ subjects had met lifetime criteria for $\mathrm{AD}$ of whom 2,109 were considered in remission (either abstinent, low-risk drinkers, or "asymptomatic risk drinkers"). Re-interviews in wave 2 (2004/2005) were done in 1,772 of the 2,109 remitted subjects. As expected, abstainers had the best 3-year full remission stability (93\%), but the low-risk drinkers and the asymptomatic risk drinkers also showed stability of 73 and $49 \%$, re- 
spectively [49]. Most of the difference was carried by long-term abstainers (15+ years of abstinence) that were very unlikely to relapse during the 3-year follow-up. A recent analysis of the predictors of the DSM- 5 alcohol use disorder in the smaller Dutch general population NEMESIS cohort showed complementary findings: the cumulative relapse rate 20 years after initial remission was low (12\%); relapse risk was associated with past alcohol drinking level and lifetime number of alcohol use disorder symptoms [50].

\section{Controlled Psychotherapy Trials with an Explicit Reduction Goal}

The best known (and most controversial) study of psychotherapy with an explicit reduction goal was published by Sobell and Sobell [51], who randomized 70 "gamma alcoholics" to either a treatment as usual control group following an abstinence goal or to a behavioral self-control program aiming at "controlled drinking." Two years later, both groups did equally well, but of those who went back to drinking in the experimental group $23 \%$ of patients were able to drink in a "controlled" way compared to only $4 \%$ in the control group. These results were unexpected in the treatment field, and the authors were accused of bias and unprofessional conduct (for details, see [52]). At last, all accusations were proven wrong and Sobell [53] noted in retrospect that the discussion would have been less emotional had they chosen the term "return to low-risk-drinking" instead of "controlled drinking".

Similarly, Sanchez-Craig et al. [54] randomized 70 problem drinkers to cognitive behavioral treatment directed either to abstinence or controlled drinking. Follow-ups at 6 months and 2 years showed equally good improvement in both groups (no significant difference). More recently, a meta-analysis on 17 behavioral self-control training randomized controlled studies including patients with $\mathrm{AD}$ or problem drinking found a combined effect size across all studies was 0.33 [55]. The author found no difference between studies with alcohol-dependent patients versus problem drinkers who did not necessarily meet criteria for $\mathrm{AD}$.

More generally, it may be important to consider the patient treatment goal in evaluating whether alcohol treatment is effective in producing reductions in alcohol consumption. For example, patient preferences for drinking goals were taken into account in the United Kingdom Alcoholism Treatment Trial. All 742 participants were spe- cifically asked for their goal before treatment onset (abstinence or moderation) [45]. At the 12-month follow-up, $10 \%$ of the initially non-abstinent goal group was indeed abstinent versus $21.2 \%$ in the abstinent goal group [46]. Moderate drinking with "no problems" was reported by $12.8 \%$ in the non-abstinent goal group versus $8.5 \%$ in the group with an abstinence goal. Taken together, improvement to "no problems" (including abstinence) was noted in $22.8 \%$ of the non-abstinent goal group versus $29.7 \%$ in the abstinent goal group [46]. These findings are consistent with a re-analysis of the COMBINE study data, which also found that individuals who selected an abstinence goal were more likely to be abstinent at follow-up [56]. It is important to note that the COMBINE study inquired about abstinence versus moderate drinking goals, however, the treatment was abstinence-focused. Moreover, the results from Bujarski et al. [56] also indicated that those who selected a moderate drinking goal had significantly lower drinking intensity on occasions of drinking than those who selected (and violated) an abstinence goal.

\section{Pharmacotherapy Trials Supporting the Reduction Concept}

Traditionally, alcohol medicines have been approved by regulatory agencies, including the US Food and Drug Administration and the EMA, for their ability to promote abstinence. For most of the 20th century, only one medication, disulfiram, was approved for use in the treatment of AD in Europe and the US. Disulfiram inhibits the acetaldehyde dehydrogenase enzyme and interferes with alcohol metabolism. As such, any drinking while taking disulfiram is contraindicated and disulfiram is only used and effective in promoting abstinence while taking the drug [57].

In the late 20th century, more alcohol medications were tested and approved for use in the treatment of $\mathrm{AD}$, and several other medications have been used off-label. For a broader description of commonly used alcohol medicines, we refer interested readers to recent reviews of available pharmacotherapies $[4,58-61]$ and their level of acceptance in different European countries [62]. The current review focuses explicitly on medicines that have shown benefit in promoting reductions in alcohol use. For example, acamprosate is effective in supporting abstinence following detoxification [63], however, it has not been shown to be superior to placebo in reducing alcohol consumption (as opposed to abstinence) [58]. It should also be noted that numerous randomized clinical trials of 
alcohol medicines for $\mathrm{AD}$ have been problematic with respect to smaller sample sizes, analysis decisions, and reporting design characteristics $[64,65]$, thus more work in this area is needed.

Oral naltrexone: two pivotal trials using naltrexone showed a benefit over placebo and led the Food and Drug Administration to approve naltrexone for the treatment of $\mathrm{AD}$ in 1992 [66, 67]. As the trial endpoint for men was "relapse" to heavy drinking defined as 5 or more drinking days per week or 5 or more drinks on a single occasion, this endpoint allowed for subthreshold consumption and can be seen as an early step towards acceptance of moderation goals. "If return to any drinking had been the endpoint, no difference between naltrexone and placebo would have been found and the drug would not have been approved" [68]. The larger COMBINE study $(n=1,383)$ [69] and a Cochrane review [70] have provided evidence in support of oral naltrexone as a medication to reduce heavy drinking and number of drinking days, although there are some negative studies [71] and the effective sizes for naltrexone appear to be attenuating over time [72].

Injectable naltrexone: injectable naltrexone has received support for reducing drinking and supporting abstinence, and thus may be useful for treating a variety of patients with AD. Kranzler et al. [73] treated 315 patients with monthly injections of $300 \mathrm{mg}$ naltrexone over 3 months. Patients were problem drinkers, but the majority fulfilled DSM-IV criteria for dependence. They were detoxified prior to study entry; follow-up was done after 3 months. The predefined endpoint (time to first heavy drinking day) showed no difference between injectable naltrexone and placebo. Secondary analyses reported a higher abstinence rate, reduced drinking, and a significantly longer period to the first drink (not heavy drinking) in favor of the medication. Garbutt et al. [74] investigated 624 patients over 6 months with a 6 -month follow-up. Patients received either 190 or $380 \mathrm{mg}$ of injectable naltrexone or placebo. No intention to abstain was required and patients could be included while drinking or while being abstinent. The event rate of heavy drinking declined in the $380 \mathrm{mg}$ group by $25 \%(p<0.05)$ and in the $190 \mathrm{mg}$ group by $17 \%(p=0.07)$. More recent reviews, including a Cochrane review [70], have been cautious about the efficacy of injectable naltrexone, given the limited longitudinal data and few large-scale studies.

Cholinergic agents: galantamine was the first cholinergic drug tested in patients with $\mathrm{AD}$ [75]. After detoxification, 149 abstinent patients were randomized to galantamine or placebo (one patch per day) over 24 weeks. The placebo group did significantly better in time to first

Reduced Drinking in AD Treatment heavy drinking day than patients on galantamine [75]. However, secondary analyses of patients who had relapsed in both groups revealed the same number of drinking days, but significantly lower alcohol consumption with galantamine [76]. Varenicline, an alpha4beta2 nicotinic receptor partial agonist, is labeled for smoking cessation in most countries [77]. Preclinical animal studies and human trials, and also observational studies have shown that varenicline can reduce alcohol use in heavydrinking smokers [78, 79]. Randomized placebo-controlled trials exploring the efficacy of varenicline in alcohol use disorders have shown inconclusive results [78]. The largest trial of patients with $\mathrm{AD}(n=200)$ showed a significant benefit of varenicline compared to placebo on percent heavy drinking days, drinks per day, drinks per drinking day, and alcohol craving [80]. The most recent trial of patients with $\mathrm{AD}(n=160)$ [81] did not find significant effects of varenicline over placebo on self-reported drinking outcomes, but did find effects on biomarkers of drinking.

\section{Review of Pharmacotherapy Trials Prospectively Testing an Explicit Reduction Goal}

The potential mechanism of reduced drinking has been described in the 1970s by Sinclair [82]. They suggested that alcohol consumption as a learned behavior can be extinguished when the expected response repeatedly does not occur. Pharmacologically, this can be done by blocking the reinforcing effects of alcohol with opioid antagonists. This hypothesis derived from studies in rodents [83] was supported by studies in primates [84]. Hence, an opioid antagonist such as naltrexone or nalmefene (reviewed below) can only exert its therapeutic effect on drinking patients and no extinction is expected among abstinent individuals. Thus, drinking reduction, but not abstinence, may be critical for the effectiveness of certain pharmacotherapies for AD. Given the considerable number of controversies in this topic, we chose to provide a narrative review. We investigated whether reductions in alcohol use following pharmacological treatment can be observed among patients with $\mathrm{AD}$. The goal of this review was to extend and update existing papers (such as by van Amsterdam and van den Brink [4]). We performed a search of PubMed, Google Scholar, Google Books, and references from relevant articles using the search terms "Alcohol dependence," "Alcohol use disorders," "Alcoholism," "Harm reduction," "Harm," "Abstinence," "Controlled drinking," "Moderation," "Heavy

Eur Addict Res 2017;23:219-230 
Table 3. Examples of controlled pharmacotherapy studies assessing a reduction goal

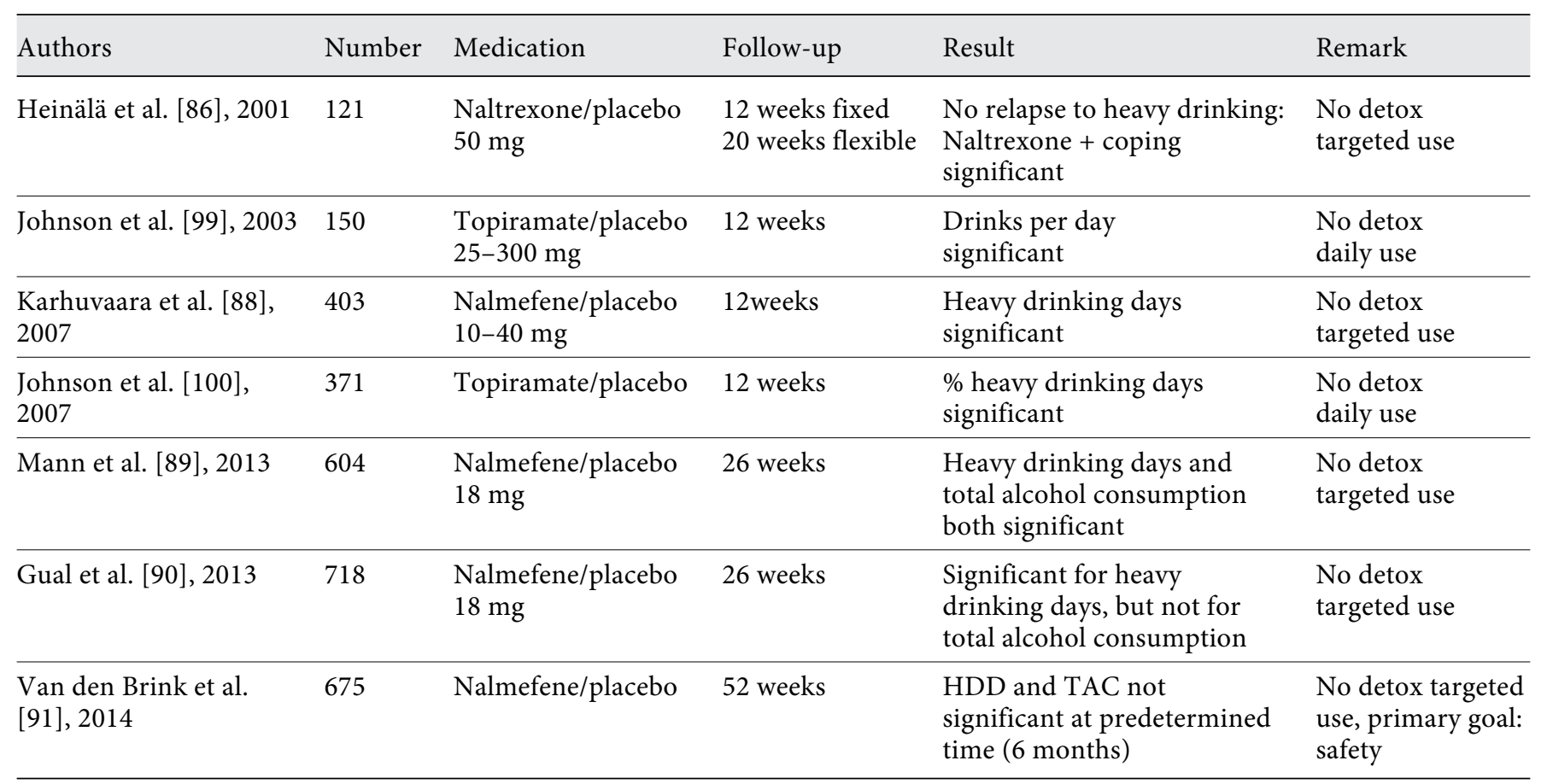

drinking." Using the same search strategy, we also selected relevant high-quality systematic reviews, meta-analyses, cohort studies, and population surveys. Selection criteria included articles published in English, German or French; with search years from 1990 to 2017.

Naltrexone: building upon a study with early problem drinkers who were given targeted naltrexone [85], Heinälä et al. [86] were the first to prospectively test this approach in alcohol-dependent non-abstinent patients. They treated 121 subjects with placebo or a fixed dose of naltrexone for 12 weeks and targeted medication (when craving occurred) for another 20 weeks. Patients were also randomized to either coping skills or supportive therapy. After 12 weeks of fixed dosage, the naltrexone plus coping skills group did best with $27 \%$ no heavy drinking days versus $3 \%$ in the placebo plus coping skills group. This difference remained throughout the 20 weeks targeted use of naltrexone (Table 3).

Nalmefene: this drug was tested in nine controlled trials, 4 of which looked prospectively at alcohol reduction with a targeted medication use (for details, see Table 3 and [87]). Patients did not undergo detoxification and were allowed to continue drinking alcohol. Nalmefene or placebo was supposed to be taken prior to an imminent consumption of alcohol ("targeted use"). Two studies showed a significant benefit in both primary endpoints
$[88,89]$, one study in the reduction of heavy drinking days but not in total alcohol consumption [90], and the other 1-year safety study that was not significant at the predefined endpoint [91]. Several meta-analyses on the ITT analyses are available now, but many were not based on the specific population defined by the EMA approved indication ("targeted use in high-risk level drinking alcohol-dependent patients"), see $[92,93]$, and only the most recent takes the EMA-approved indication of nalmefene into account [87]. Here the average effect size for "the EMA indication" was 0.33 , for the ITT population it was 0.20 [87].

Despite the efficacy in reducing heavy drinking among high-risk drinking level patients with $\mathrm{AD}$, there is an ongoing debate in the field about the efficacy of nalmefene and on the process of approval [94]. Given the large number of heavy drinkers with $\mathrm{AD}$ who are not seeking treatment because they do not want to pursue an abstinence goal $[30,31]$, we feel the nalmefene debate needs to be considered within the larger context of a public health approach to the treatment of $\mathrm{AD}$ [95]. A recent micro-simulation study provides further support for nalmefene as a medication that could significantly reduce morbidity and mortality related to alcohol use [96].

Topiramate: this medication is approved as an antiepileptic drug. It is supposed to interact with alcohol's 
reinforcing effects on the brain [97]. A recent meta-analysis found topiramate to be more effective than placebo in promoting abstinence and reducing heavy drinking, with effect sizes that exceeded those of acamprosate, nalmefene, and naltrexone [98]. Of greatest relevance to this review, 3 studies tested topiramate against placebo with the explicit goal of reducing alcohol. In all 3 studies, patients had no a priori detoxification and were allowed to continue drinking alcohol. Results of a single center pilot study as well as a large multicenter study showed reductions in both groups with a significant difference in favor of topiramate $[99,100]$. Results were recently supported in a sample of heavy drinkers as well [101] with a significant advantage found for topiramate in the EuropeanAmerican subsample $(n=122)$ with a moderation effect of a single nucleotide polymorphism (rs2832407) in GRIK1, encoding the kainate GluK1 receptor subunit. Importantly, a recent secondary analysis found that the clinical efficacy of topiramate for reducing heavy drinking was supported even after adjusting for adverse events [102].

\section{Consideration of New Clinical Guidance and Endpoints for AD Treatment}

We believe the studies highlighted above illustrate how clinical trials designs progressively changed from abstinence maintenance or relapse prevention orientation to alcohol reduction without prior detoxification. Looking at a broader picture, a systematic review of naltrexone trials in $\mathrm{AD}$ published in 2006 showed that $70 \%$ of the trials that measured reductions in heavy drinking days found a superiority of naltrexone over placebo, whereas less than $40 \%$ of the trials that measured abstinence demonstrated a superiority of naltrexone [103]. The value of alcohol reduction endpoints was confirmed later by meta-analysis that showed that, compared to acamprosate, naltrexone is mainly effective in preventing heavy drinking, rather than maintaining abstinence [92, 104]. Consistent with these findings, an earlier systematic review searching PubMed, Embase, ClinicalTrials. gov, and the R\&D Insight and Clinical Trials Insight databases identified a trend whereby more recent ongoing/ unpublished trials were more likely to focus on alcohol reduction outcomes among patients who are actively drinking, as compared to older trials, which mostly focused on abstinence outcomes among patients who were detoxified and abstinent at the start of treatment [105]. Importantly, addiction treatment providers have also ac- cepted the non-abstinence goals, particularly for patients with AD [106].

The oldest evidence-based guidelines referred to in this review come from Australia [107]. They are less specific than later guidelines mentioned below regarding harm reduction. Abstinence is considered the most realistic drinking goal for patients with severe $\mathrm{AD}$, and/or with a significant level of comorbidity. The possibility that these patients may be reluctant to engage in abstinence should be dealt with by more intense "negotiations," which may involve a period of moderate drinking, to eventually lead the patient to engage in abstinence.

In the United Kingdom, the NICE guidelines investigated the scientific basis for treatment recommendations in problematic alcohol use [26]. Although their work was done before some of the recent empirical data relevant to the question of reduced drinking for alcohol-dependent individuals were published, their conclusions include recommendations for harm reduction under certain conditions (Table 4) [108] and are globally accepted as relevant recommendations in this matter. For example, the NICE recommendations have been accepted by the French guidelines [109-111] and in the German guidelines put together by a representative group of stakeholders from Germany, Switzerland, and Austria $[112,113]$.

Similar statements regarding treatment goals and harm reduction strategies can be found in older recommendations, such as the NIAAA clinician's guide (Table 5) [114]. All guidelines recommend to avoid drinking over "low-risk drinking" limits. However, the definitions of these limits differ across countries [115]. The World Health Organization, who has proposed 4 risk drinking levels for acute problems and 3 risk drinking levels for chronic harm (Table 1) $[1,2]$, may be more useful in defining a positive treatment response across countries, given the risk levels are defined by grams per day. Based on these WHO levels, the EMA has defined responder criteria for trials testing medications for $\mathrm{AD}$. The definition of a positive treatment response is listed in Table 6 . An example can be found in a responder analysis of the recent nalmefene trials [95].

Two recent studies have provided validation of the WHO endpoint. Analysis of the US population-based NESARC data $[41,116]$, already referred to above found reduced alcohol consumption, based on at least a onelevel reduction in WHO risk level of drinking (Table 1) from wave 1 to wave 2 conveys significant benefits in the course of 3 years in terms of lower prevalence of AD. Similarly, a recent analysis based on the large US COMBINE study data $(n=1,383)$, which examined 
Table 4. Treatment goals, as proposed in the UK NICE guidelines (2011) [108] also adopted by the German guidelines (2016) [112]

1. In the initial assessment in specialist alcohol services of all people who misuse alcohol, agree the goal of treatment with the service user. Abstinence is the appropriate goal for most people with alcohol dependence, and people who misuse alcohol, and have significant psychiatric or physical comorbidity (e.g., depression or alcohol-related liver disease). When a service user prefers a goal of moderation but there are considerable risks, advise strongly that abstinence is most appropriate, but do not refuse treatment to service users who do not agree to a goal of abstinence.

2. For harmful drinking or mild dependence, without significant comorbidity, and if there is adequate social support, consider a moderate level of drinking as the goal of treatment unless the service user prefers abstinence or there are other reasons for advising abstinence.

3. For people with severe alcohol dependence, or those who misuse alcohol and have significant psychiatric or physical comorbidity, but who are unwilling to consider a goal of abstinence or engage in structured treatment, consider a harm reduction program of care. However, ultimately the service user should be encouraged to aim for a goal of abstinence.

4. When developing treatment goals, consider that some people who misuse alcohol may be required to abstain from alcohol as part of a court order or sentence.

Table 5. Clinical guidelines issued by the US National Institute on Alcohol Abuse and Alcoholism (NIAAA 2005) [114]

“...Abstaining is the safest course for most patients with alcohol use disorders. [...] Still, it is best to determine individualized goals with each patient. Some patients may not be willing to endorse abstinence as a goal, especially at first. If an alcohol-dependent patient agrees to reduce drinking substantially, it is best to engage them in that goal while continuing to note that abstinence remains in the optimal outcome."

Table 6. Guidance paper of the European Medicines Agency, 2010 [1]

"As the key secondary endpoint efficacy should also be evaluated in terms of responders, reflecting an expected significant improved health outcome on an individual patient level. This could be done by evaluating the proportion of subjects with a 50,70 , and $90 \%$ reduction in alcohol consumption as well as the proportion of patients achieving maintained abstinence. Another option would be evaluating the proportion of subjects with a significant categorical shift in WHO risk levels of drinking (i.e., proportion of patients with change of consumption to baseline from very high risk to at least medium risk level and change from high risk to at least low risk level, as well as the proportion of patients with full abstinence).”

combinations of pharmacotherapy and behavioral interventions for patients with $\mathrm{AD}$, also found reductions in alcohol consumption, based on reductions in the WHO risk levels of drinking (Table 1) were associated with significant improvements in areas, such as mental health and consequences of drinking [117]. Specifically, even a one-level reduction in risk level of drinking from baseline to the end of the 16 weeks treatment period in COMBINE was associated with very large effect size reductions in alcohol-related problems and large effect size improvements in mental health functioning up to 1 year following treatment. Together, the analysis of the WHO risk level changes in the COMBINE study [64] and in the NESARC study [116] support earlier studies showing that alcohol reduction leads to a substantial re- duction of mortality risk and a reduction of morbidity [118-120], as well as an increase in the quality of life [121-124].

\section{Summary and Conclusions}

Abstinence from any alcohol remains the safest treatment option for individuals with $\mathrm{AD}$; patients who achieve abstinence are more likely to remain in long-term remission than subjects who return to asymptomatic drinking. However, observational studies have shown that non-abstinent remission from alcohol use disorders is frequent and more stable than expected earlier. In patients seeking treatment, psychotherapy trials have shown 
that patients' drinking goal often relates to alcohol use disorder severity, and also to the type of outcome achieved, that is, moderation outcome is linked to moderation goal and abstinence outcome is related to abstinence goal.

Pharmacotherapy trials have traditionally aimed at complete abstinence, or - mainly in the USA - relapse prevention (no heavy drinking day) after a period of detoxification. A retrospective examination of studies performed before the turn of the century show that opioid antagonists have some efficacy in reducing alcohol intake, although the patients were instructed to avoid any drinking.

More recently, an increasing number of trials were designed to explicitly aim for a reduction goal. A number of placebo-controlled trials enrolling alcohol-dependent patients have confirmed that a 6-12 months stable reduction is achieved, even in placebo-treated subjects, and that the outcome can be significantly improved with opioid modulators (naltrexone, nalmefene), topiramate, or other drugs (with no replication publications yet).

Following the successful results of European studies, the EMA and other medicines regulation authorities are considering adopting less stringent endpoints when examining the labeling of medications for $\mathrm{AD}$, leaving more possibilities for the development of a new avenue in the pharmacotherapy of $\mathrm{AD}$.
Along with this trend, alcohol treatment guidelines are also including alcohol reduction as an alternative drinking goal in alcohol-dependent patients, along with abstinence. The NIAAA guidelines were probably first to advocate for individualized treatment goals, and accept reduction in alcohol-dependent patients unwilling to engage in abstinence. UK NICE elaborated more on this, also recommending that the therapist should agree to the patient's treatment goal in the initial assessment. Importantly, these guidelines emphasize that a harm reduction approach is far better than status quo.

\section{Acknowledgements}

The authors received no funding to write this review. No medical writer was commissioned.

\section{Disclosure Statement}

K.M. is a member of the advisory boards for Pfizer and Lundbeck and has received speaker fees from Lundbeck. H.-J.A. is a member of advisory boards for Pfizer, D\&A Pharma, Ethypharm, and Lundbeck, and has received sponsorship to attend scientific meetings, speaker honoraria, and consultancy fees from Bioprojet, D\&A Pharma, Ethypharm, Lundbeck, Merck-Serono, Novartis, and Pfizer. Dr. Witkiewitz has no conflicts of interest.

\section{References}

1 European-Medicines-Agency: Guideline on the Development of Medicinal Products for the Treatment of Alcohol Dependence. 2010. http://www.ema.europa.eu/docs/en_GB/ document_library/Scientific_guideline/2010/03/WC500074898.pdf (cited 2012).

2 World-Health-Organization (WHO): International Guide for Monitoring Alcohol Consumption and Related Harm. 2000. http:// whqlibdoc.who.int/hq/2000/WHO_MSD_ MSB_00.4.pdf.

3 Maremmani I, Cibin M, Pani PP, Rossi A, Turchetti G: Harm reduction as "continuum care" in alcohol abuse disorder. Int J Environ Res Public Health 2015;12:14828-14841.

4 van Amsterdam J, van den Brink W: Reduced-risk drinking as a viable treatment goal in problematic alcohol use and alcohol dependence. J Psychopharmacol 2013;27:987-997.

5 Rehm J, Mathers C, Popova S, Thavorncharoensap M, Teerawattananon Y, Patra J: Global burden of disease and injury and economic cost attributable to alcohol use and alcoholuse disorders. Lancet 2009;373:2223-2233.

6 World-Health-Organization: Global Status Report on Alcohol and Health. World Health Organization, 2014.
7 Rehm J, Baliunas D, Borges GL, Graham K, Irving H, Kehoe T, Parry CD, Patra J, Popova S, Poznyak V, Roerecke M, Room R, Samokhvalov AV, Taylor B: The relation between different dimensions of alcohol consumption and burden of disease: an overview. Addiction 2010;105:817-843.

8 Roerecke M, Rehm J: The cardioprotective association of average alcohol consumption and ischaemicheart disease: a systematic review and meta-analysis. Addiction 2012;107:1246-1260.

9 Baliunas DO, Taylor BJ, Irving H, Roerecke M, Patra J, Mohapatra S, Rehm J: Alcohol as a risk factor for type 2 diabetes: a systematic review and meta-analysis. Diabetes Care 2009; 32:2123-2132.

10 Kerr WC, Greenfield TK, Bond J, Ye Y, Rehm $\mathrm{J}$ : Racial and ethnic differences in all-cause mortality risk according to alcohol consumption patterns in the national alcohol surveys. Am J Epidemiol 2011;174:769-778.

11 Rehm J, Zatonksi W, Taylor B, Anderson P: Epidemiology and alcohol policy in Europe. Addiction 2011;106(suppl 1):11-19.

12 Stockwell T, Zhao J, Panwar S, Roemer A, Naimi T, Chikritzhs T: Do "Moderate" drinkers have reduced mortality risk? A systematic review and meta-analysis of alcohol consumption and all-cause mortality. J Stud Alcohol Drugs 2016;77:185-198.

13 Knott CS, Coombs N, Stamatakis E, Biddulph JP: All cause mortality and the case for age specific alcohol consumption guidelines: pooled analyses of up to 10 population based cohorts. BMJ 2015;350:h384.

14 Zhao J, Stockwell T, Roemer A, Naimi T, Chikritzhs T: Alcohol consumption and mortality from coronary heart disease: an updated meta-analysis of cohort studies. J Stud Alcohol Drugs 2017;78:375-386.

15 Di Castelnuovo A, Costanzo S, Bagnardi V, Donati MB, Iacoviello L, de Gaetano G: Alcohol dosing and total mortality in men and women: an updated meta-analysis of 34 prospective studies. Arch Intern Med 2006;166:2437-2445.

16 Rehm J, Gmel G, Sempos CT, Trevisan M: Alcohol-related morbidity and mortality. Alcohol Res Health 2003;27:39-51.

17 Midlov P, Calling S, Memon AA, Sundquist J, Sundquist K, Johansson SE: Women's health in the Lund area (WHILA) - Alcohol consumption and all-cause mortality among women - a 17 year follow-up study. BMC Public Health 2016;16:22. 
18 Shield KD, Gmel G, Makela P, Probst C, Room R, Rehm J: Life-time risk of mortality due to different levels of alcohol consumption in seven European countries: implications for low-risk drinking guidelines. Addiction 2017; 112:1535-1544.

19 Charlet K, Heinz A: Harm reduction-a systematic review on effects of alcohol reduction on physical and mental symptoms. Addict Biol 2016;22:1119-1159.

20 Marlatt GA, Witkiewitz K: Update on harmreduction policy and intervention research. Annu Rev Clin Psychol 2010;6:591-606.

21 Marlatt GA: Basic principles and strategies of harm reduction; in Marlatt GA (ed): Harm Reduction, Pragmatic Strategies for Managing High-Risk Behaviors. New York, Guilford Press, 1998, pp 69-121.

22 Heather N, Wodak A, Nadelmann E, O'Hare P: Psychoactive Drugs and Harm Reduction: from Faith to Science. London, WHURR, 1992.

23 Marlatt GA, Witkiewitz K: Harm reduction approaches to alcohol use: health promotion, prevention, and treatment. Addict Behav 2002;27:867-886.

24 Raistrick D, Heather N, Godfrey C: Review of the Effectiveness of Treatment for Alcohol Problems. London, National Treatment Agency for Substance Misuse, 2006.

25 Davey CJ, Landy MS, Pecora A, Quintero D, McShane KE: A realist review of brief interventions for alcohol misuse delivered in emergency departments. Syst Rev 2015;4:45.

26 Fava GA, Visani D: Psychosocial determinants of recovery in depression. Dialogues Clin Neurosci 2008; 10:461-472.

27 Kohn R, Saxena S, Levav I, Saraceno B: The treatment gap in mental health care. Bull World Health Organ 2004;82:858-866.

28 Cohen E, Feinn R, Arias A, Kranzler HR: Alcohol treatment utilization: findings from the national epidemiologic survey on alcohol and related conditions. Drug Alcohol Depend 2007;86:214-221.

29 Rumpf HJ, Meyer C, Hapke U, Bischof G, John U: Utilization of Professional Help of Individuals with Alcohol Dependence or Abuse: Findings from the TACOS-General Population Study. SUCHT, 2000, Vol. 46, pp 9-17. https://doi.org/10.1024/suc.2000.46.1.9.

30 Substance Abuse and Mental Health Services Administration Office of Applied Studies. The NSDUH report: Alcohol Treatment: Need, utilization, and Barriers. Rockville, MD, April 9, 2009. http://www.samhsa.gov/ data/2k9/AlcTX/AlcTX.htm (cited 2009).

31 Substance Abuse and Mental Health Services Administration: Results from the $2013 \mathrm{Na}$ tional Survey on Drug Use and Health: Summary of National Findings. Rockville, Substance Abuse and Mental Health Services Administration, 2014.

32 Tuithof M, Ten Have M, van den Brink W, Vollebergh W, de Graaf R: Treatment Seeking for alcohol use disorders: treatment gap or adequate self-selection? Eur Addict Res 2016;22: 277-285.
33 Institute of Medicine: Broadening the Base of Treatment for Alcohol Problems. Washington, The National Academies Press, 1990.

34 Mann K, Kiefer F, Smolka M, Gann H, Wellek S, Heinz A: Searching for responders to acamprosate and naltrexone in alcoholism treatment: rationale and design of the PREDICT study. Alcohol Clin Exp Res 2009;33:674683.

35 Tatarsky A: Harm Reduction Psychotherapy: A New Treatment for Drug and Alcohol Problems: Jason Aronson, Incorporated, 2007.

36 Larimer ME, Marlatt GA, Baer JS, Quigley LA, Blume AW, Hawkins EH: Harm reduction for alcohol problems; in Marlatt A, Larimer ME, Witkiewitz K (eds): Harm Reduction, Second Edition: Pragmatic Strategies for Managing High-Risk Behaviors. New York, Guilford Press, 2011, pp 62-105.

37 Dawson DA, Goldstein RB, Grant BF: Rates and correlates of relapse among individuals in remission from DSM-IV alcohol dependence: a 3-year follow-up. Alcohol Clin Exp Res 2007;31:2036-2045.

38 Witkiewitz K, Dearing RL, Maisto SA: Alcohol use trajectories among non-treatment seeking heavy drinkers. J Stud Alcohol Drugs 2014;75:415-422.

39 Vaillant GE: A 60-year follow-up of alcoholic men. Addiction 2003;98:1043-1051.

40 Vaillant GE: The Natural History of Alcoholism. Harvard University Press, 1983.

41 Mann K, Schafer DR, Langle G, Ackermann $\mathrm{K}$, Croissant $\mathrm{B}$ : The long-term course of alcoholism, 5, 10 and 16 years after treatment. Addiction 2005;100:797-805.

42 Nordstrom G, Berglund M, Frank A: Stability of successful long-term adjustment in alcohol dependence: a follow-up study 15 years after the first long-term follow-up. Eur Addict Res 2004;10:126-132.

43 Maisto SA, Clifford PR, Stout RL, Davis CM: Moderate drinking in the first year after treatment as a predictor of three-year outcomes. J Stud Alcohol Drugs 2007;68:419-427.

44 Witkiewitz K: Lapses following alcohol treatment: modeling the falls from the wagon. J Stud Alcohol Drugs 2008;69:594-604.

45 Heather N, Adamson SJ, Raistrick D, Slegg GP; UKATT Research Team: Initial preference for drinking goal in the treatment of alcohol problems: I. Baseline differences between abstinence and non-abstinence groups. Alcohol Alcohol 2010;45:128-135.

46 Adamson SJ, Heather N, Morton V, Raistrick D; UKATT Research Team: Initial preference for drinking goal in the treatment of alcohol problems: II. Treatment outcomes. Alcohol Alcohol 2010;45:136-142.

47 Ojehagen A, Berglund M: Changes of drinking goals in a two-year out-patient alcoholic treatment program. Addict Behav 1989;14: $1-9$.

48 Witkiewitz K, Wilson AD, Pearson MR, Hallgren KA, Falk DE, Litten RZ, Kranzler HR, Mann KF, Hasin DS, O’Malley SS, Anton RF:
Temporal stability of heavy drinking days and drinking reductions among heavy drinkers in the COMBINE study. Alcohol Clin Exp Res 2017;10:13371.

49 Dawson DA, Li TK, Chou SP, Grant BF: Transitions in and out of alcohol use disorders: their associations with conditional changes in quality of life over a 3-year follow-up interval. Alcohol Alcohol 2009;44:84-92.

50 Tuithof $M$, ten Have M, van den Brink W, Vollebergh W, de Graaf R: Alcohol consumption and symptoms as predictors for relapse of DSM-5 alcohol use disorder. Drug Alcohol Depend 2014;140:85-91.

51 Sobell MB, Sobell LC: Alcoholics treated by individualized behavior therapy: one year treatment outcome. Behav Res Ther 1973;11: 599-618.

52 Ambrogne JA: Reduced-risk drinking as a treatment goal: what clinicians need to know. J Subst Abuse Treat 2002;22:45-53.

53 Sobell MB, Sobell LC: It is time for low-risk drinking goals to come out of the closet. Addiction 2011;106:1715-1717.

54 Sanchez-Craig M, Annis HM, Bornet AR, MacDonald KR: Random assignment to abstinence and controlled drinking: evaluation of a cognitive-behavioral program for problem drinkers. J Consult Clin Psychol 1984;52: 390-403.

55 Walters GD: Behavioral self-control training for problem drinkers: a meta-analysis of randomized control studies. Behavior Therapy 2000;31:135-149.

56 Bujarski S, O’Malley SS, Lunny K, Ray LA: The effects of drinking goal on treatment outcome for alcoholism. J Consult Clin Psychol 2013;81:13-22.

57 Jørgensen CH, Pedersen B, Tønnesen H: The efficacy of disulfiram for the treatment of alcohol use disorder. Alcohol Clin Exp Res 2011;35:1749-1758.

58 Zindel LR, Kranzler HR: Pharmacotherapy of alcohol use disorders: seventy-five years of progress. J Stud Alcohol Drugs Suppl 2014; 75(suppl 17):79-88.

59 Müller CA, Geisel O, Banas R, Heinz A: Current pharmacological treatment approaches for alcohol dependence. Expert Opin Pharmacother 2014;15:471-481.

60 Franck J, Jayaram-Lindström N: Pharmacotherapy for alcohol dependence: status of current treatments. Curr Opin Neurobiol 2013; 23:692-699.

61 Jonas DE, Amick HR, Feltner C, Bobashev G, Thomas K, Wines R, Kim MM, Shanahan E, Gass CE, Rowe CJ, Garbutt JC: Pharmacotherapy for adults with alcohol use disorders in outpatient settings: a systematic review and meta-analysis. JAMA 2014;311:18891900.

62 Bramness JG, Mann K, Wurst FM: Marketing status and perceived efficacy of drugs for supporting abstinence and reducing alcohol intake in alcohol use disorders: a survey among European federation of addiction societies in Europe. Eur Addict Res 2016;22:318-321. 
63 Rösner S, Hackl-Herrwerth A, Leucht S, Lehert P, Vecchi S, Soyka M: Acamprosate for alcohol dependence. Cochrane Database Syst Rev 2010;9:CD004332.

64 Witkiewitz K, Finney JW, Harris AH, Kivlahan DR, Kranzler HR: Guidelines for the reporting of treatment trials for alcohol use disorders. Alcohol Clin Exp Res 2015;39:15711581.

65 Witkiewitz K, Finney JW, Harris AH, Kivlahan DR, Kranzler HR: Recommendations for the design and analysis of treatment trials for alcohol use disorders. Alcohol Clin Exp Res 2015;39:1557-1570.

66 O'Malley SS, Jaffe AJ, Chang G, Schottenfeld RS, Meyer RE, Rounsaville B: Naltrexone and coping skills therapy for alcohol dependence. A controlled study. Arch Gen Psychiatry 1992;49:881-887.

67 Volpicelli JR, Alterman AI, Hayashida M, O'Brien CP: Naltrexone in the treatment of alcohol dependence. Arch Gen Psychiatry 1992;49:876-880.

68 O'Brien C, Pettinati H, Oslin D: Naltrexone: clinical data; in Spanagel R, Mann KF (eds): Drugs for Relapse Prevention of Alcoholism. Birkhäuser, Basel, 2006.

69 Anton RF, O'Malley SS, Ciraulo DA, Cisler RA, Couper D, Donovan DM, Gastfriend DR, Hosking JD, Johnson BA, LoCastro JS, Longabaugh R, Mason BJ, Mattson ME, Miller WR, Pettinati HM, Randall CL, Swift R, Weiss RD, Williams LD, Zweben A; COMBINE Study Research Group: Combined pharmacotherapies and behavioral interventions for alcohol dependence: the COMBINE study: a randomized controlled trial. JAMA 2006;295:20032017.

70 Rösner S, Hackl-Herrwerth A, Leucht S, Vecchi S, Srisurapanont M, Soyka M. Opioid antagonists for alcohol dependence. Cochrane Database Syst Rev 2010;12:CD001867.

71 Krystal JH, Cramer JA, Krol WF, Kirk GF, Rosenheck RA; Veterans Affairs Naltrexone Cooperative Study G 425 Group: Naltrexone in the treatment of alcohol dependence. $\mathrm{N}$ Engl J Med 2001;345:1734-1739.

72 Del Re AC, Maisel N, Blodgett J, Finney J: The declining efficacy of naltrexone pharmacotherapy for alcohol use disorders over time: a multivariate meta-analysis. Alcohol Clin Exp Res 2013;37:1064-1068.

73 Kranzler HR, Wesson DR, Billot L: Naltrexone depot for treatment of alcohol dependence: a multicenter, randomized, placebocontrolled clinical trial. Alcohol Clin Exp Res 2004;28:1051-1059.

74 Garbutt JC, Kranzler HR, O’Malley SS, Gastfriend DR, Pettinati HM, Silverman BL, Loewy JW, Ehrich EW; Vivitrex Study Group: Efficacy and tolerability of long-acting injectable naltrexone for alcohol dependence: a randomized controlled trial. JAMA 2005;293: $1617-1625$.

75 Mann K, Ackermann K, Diehl A, Ebert D, Mundle G, Nakovics H, Reker T, Richter G, Schmidt LG, Driessen M, Rettig K, Opitz K,
Croissant B: Galantamine: a cholinergic patch in the treatment of alcoholism: a randomized, placebo-controlled trial. Psychopharmacology (Berl) 2006;184:115-121.

76 Diehl A, Nakovics H, Croissant B, Smolka MN, Batra A, Mann K: Galantamine reduces smoking in alcohol-dependent patients: a randomized, placebo-controlled trial. Int J Clin Pharmacol Ther 2006;44:614-22.

77 Aubin HJ, Luquiens A, Berlin I: Pharmacotherapy for smoking cessation: pharmacological principles and clinical practice. $\mathrm{Br} \mathrm{J}$ Clin Pharmacol 2014;77:324-336.

78 Aubin HJ, Luquiens A: Feeding two birds with one scone: the case of varenicline. Alcohol Clin Exp Res 2015;39:2299-2301.

79 Erwin BL, Slaton RM: Varenicline in the treatment of alcohol use disorders. Ann Pharmacother 2014;48:1445-1455.

80 Litten RZ, Ryan ML, Fertig JB, Falk DE, Johnson B, Dunn KE, Green AI, Pettinati HM, Ciraulo DA, Sarid-Segal O, Kampman K, Brunette MF, Strain EC, Tiouririne NA, Ransom J, Scott C, Stout R; NCIG (National Institute on Alcohol Abuse and Alcoholism Clinical Investigations Group) Study Group: A double-blind, placebo-controlled trial assessing the efficacy of varenicline tartrate for alcohol dependence. J Addict Med 2013;7: 277-286.

81 de Bejczy A, Lof E, Walther L, Guterstam J, Hammarberg A, Asanovska G, Franck J, Isaksson A, Söderpalm B: Varenicline for treatment of alcohol dependence: a randomized, placebo-controlled trial. Alcohol Clin Exp Res 2015;39:2189-2199.

82 Sinclair JD: Evidence about the use of naltrexone and for different ways of using it in the treatment of alcoholism. Alcohol Alcohol 2001;36:2-10.

83 Sinclair JD, Scheinin H, Lammintausta R, Inventors: Method for Treating Alcoholism with Nalmefene. USA Patent 5,086,058. February $4,1992$.

84 Altshuler HL, Phillips PE, Feinhandler DA: Alteration of ethanol self-administration by naltrexone. Life Sci 1980;26:679-688.

85 Kranzler HR, Tennen H, Penta C, Bohn MJ: Targeted naltrexone treatment of early problem drinkers. Addict Behav 1997;22:431436.

86 Heinälä P, Alho H, Kiianmaa K, Lonnqvist J, Kuoppasalmi K, Sinclair JD: Targeted use of naltrexone without prior detoxification in the treatment of alcohol dependence: a factorial double-blind, placebo-controlled trial. J Clin Psychopharmacol 2001;21:287-292.

87 Mann K, Torup L, Sorensen P, Gual A, Swift $\mathrm{R}$, Walker B, van den Brink W: Nalmefene for the management of alcohol dependence: review on its pharmacology, mechanism of action and meta-analysis on its clinical efficacy. Eur Neuropsyhcopharmacol 2016;26:19411949.

88 Karhuvaara S, Simojoki K, Virta A, Rosberg M, Löyttyniemi E, Nurminen T, Kallio A, Mäkelä R: Targeted nalmefene with simple medical management in the treatment of heavy drinkers: a randomized double-blind placebo-controlled multicenter study. Alcoholism Clin Exp Res 2007;31:1179-1187.

89 Mann K, Bladstrom A, Torup L, Gual A, van den Brink W: Extending the treatment options in alcohol dependence: a randomized controlled study of as-needed nalmefene. Biol Psychiatry 2013;73:706-713.

90 Gual A, He Y, Torup L, van den Brink W, Mann K: A randomised, double-blind, placebo-controlled, efficacy study of nalmefene, as-needed use, in patients with alcohol dependence. Eur Neuropsychopharmacol 2013;23: 1432-1442.

91 van den Brink W, Sorensen P, Torup L, Mann $\mathrm{K}$, Gual A: Long-term efficacy, tolerability and safety of nalmefene as-needed in patients with alcohol dependence: a 1-year, randomised controlled study. J Psychopharmacol 2014;28:733-744.

92 Jonas DE, Amick HR, Feltner C, Bobashev G, Thomas K, Wines R, Kim MM, Shanahan E, Gass CE, Rowe CJ, Garbutt JC: Pharmacotherapy for adults with alcohol use disorders in outpatient settings: a systematic review and meta-analysis. JAMA 2014;311:18891900.

93 Palpacuer C, Laviolle B, Boussageon R, Reymann JM, Bellissant E, Naudet F: Risks and benefits of nalmefene in the treatment of adult alcohol dependence: a systematic literature review and $\mathrm{m}$-analysis of published and unpublished double-blind randomized controlled trials. PLoS Med 2015;12:e1001924.

94 Fitzgerald N, Angus K, Elders A, de Andrade M, Raistrick D, Heather N, McCambrdige J: Weak evidence on nalmefene creates dilemmas for clinicians and poses questions for regulators and researchers. Addiction 2016;111: 1477-1487.

95 Aubin HJ, Reimer J, Nutt DJ, Bladstrom A, Torup L, Francois C, Chick J: Clinical relevance of as-needed treatment with nalmefene in alcohol-dependent patients. Eur Addict Res 2015;21:160-618.

96 Laramée P, Millier A, Rahhali N, Cristeau O, Aballéa S, François C, Chalem Y, Toumi M, Rehm J: A Trial-based predictive microsimulation assessing the public health benefits of nalmefene and psychosocial support for the reduction of alcohol consumption in alcohol dependence. Appl Health Econ Health Policy 2016;14:493-505.

97 Johnson BA: Update on neuropharmacological treatments for alcoholism: scientific basis and clinical findings. Biochem Pharmacol 2008;75:34-56.

98 Blodgett JC, Del Re AC, Maisel NC, Finney JW: A meta-analysis of topiramate's effects for individuals with alcohol use disorders. Alcohol Clin Exp Res 2014;38:1481-1488.

99 Johnson BA, Ait-Daoud N, Bowden CL, Di Clemente CC, Roache JD, Lawson K, Javors MA, Ma JZ: Oral topiramate for treatment of alcohol dependence: a randomised controlled trial. Lancet 2003;361:1677-1685. 
100 Johnson BA, Rosenthal N, Capece JA, Wiegand F, Mao L, Beyers K, McKay A, AitDaoud N, Anton RF, Ciraulo DA, Kranzler HR, Mann K, O'Malley SS, Swift RM; Topiramate for Alcoholism Advisory Board; Topiramate for Alcoholism Study Group: Topiramate for treating alcohol dependence: a randomized controlled trial. JAMA 2007;298:1641-1651.

101 Kranzler HR, Covault J, Feinn R, Armeli S, Tennen H, Arias AJ, Gelernter J, Pond T, Oncken C, Kampman KM: Topiramate treatment for heavy drinkers: moderation by a GRIK1 polymorphism. Am J Psychiatry 2014;171:445-452.

102 Feinn R, Curtis B, Kranzler HR: Balancing risk and benefit in heavy drinkers treated with topiramate: implications for personalized care. J Clin Psychiatry 2016;77:e278e282.

103 Pettinati HM, O'Brien CP, Rabinowitz AR, Wortman SP, Oslin DW, Kampman KM, Dackis CA: The status of naltrexone in the treatment of alcohol dependence: specific effects on heavy drinking. J Clin Psychopharmacol 2006;26:610-625.

104 Rosner S, Leucht S, Lehert P, Soyka M: Acamprosate supports abstinence, naltrexone prevents excessive drinking: evidence from a meta-analysis with unreported outcomes. J Psychopharmacol 2008;22:11-23.

105 Aubin HJ, Daeppen JB: Emerging pharmacotherapies for alcohol dependence: a systematic review focusing on reduction in consumption. Drug Alcohol Depend 2013; 133:15-29.

106 Davis AK, Rosenberg H: Acceptance of nonabstinence goals by addiction professionals in the United States. Psychol Addict Behav 2013;27:1102-1109.

107 Haber P, Lintzeris N, Proude E, Lopatko O: Guidelines for the Treatment of Alcohol Problems. University of Sydney, June 2009.

108 NICE: Alcohol-use disorders: diagnosis, assessment and management of harmful drinking and alcohol dependence, 2011.
109 Rolland B, Paille F, Gillet C, Rigaud A, Moirand R, Dano C, Dematteis M, Mann K, Aubin HJ: Pharmacotherapy for alcohol dependence: the 2015 recommendations of the French alcohol society, issued in partnership with the European federation of addiction societies. CNS Neurosci Ther 2016;22:2537.

110 Société-Française-d'Alcoologie: Good Practice Recommendation - Alcohol Misuse: Screening, Diagnosis and Treatment. http:// www.sfalcoologie.asso.fr/download/SFAGPR-AlcoholMisuse.pdf? PHPSESSID = df10f34a9d9ef5f445823e99114a1145] (cited 2015).

111 Rolland B, Mann K, Paille F, Aubin HJ: The new French guidelines on alcohol misuse: an initiative for strengthening cross-European interplay. Addiction 2015;110:1362-1363.

112 Mann K, Batra A, Fauth-Buhler M, Hoch E: German guidelines on screening, diagnosis and treatment of alcohol use disorders. Eur Addict Res 2017;23:45-60.

113 Mann K, Hoch E, Batra A, Bonnet U, Gunthner A, Reymann G, Soyka M, Wodarz N, Schäfer M: [Guideline-oriented treatment of alcohol-related disorders]. Nervenarzt 2016; 87:13-25.

114 National Institute on Alcohol Abuse and Alcoholism: Helping Patients Who Drink Too Much. A Clinician's Guide. Washington, National Institutes of Health, US Department of Health and Human Services, 2005.

115 Kalinowski A, Humphreys K: Governmental standard drink definitions and low-risk alcohol consumption guidelines in 37 countries. Addiction 2016;13:13341.

116 Hasin DS, Wall M, Witkiewitz K, Kranzler H, Falk D, Litten R, Mann K, O’Malley S, Scodes J, Robinson RL, Anton R on behalf of the Alcohol Clinical Trials Initiative (ACTIVE) Workgroup: Change in non-abstinent WHO risk drinking levels and alcohol dependence: a 3-Year follow-up study in the US General Population. Lancet Psychiatry 2017;4:469-476
117 Witkiewitz K, Hallgren KA, Kranzler HR, Mann KF, Hasin DS, Falk DE, Litten RZ, O'Malley SS, Anton RF: Clinical validation of reduced alcohol consumption after treatment for alcohol dependence using the world health organization risk drinking levels. Alcohol Clin Exp Res 2017;41:179-186.

118 Kline-Simon AH, Litten RZ, Weisner CM, Falk DE: Post-treatment low-risk drinking as a predictor of future drinking and problem outcomes among individuals with alcohol use disorders: a 9-year follow-up. Alcohol Clin Exp Res 2017;10:13334.

119 Miquel L, Gual A, Vela E, Lligoña A, Bustins M, Colom J, Rehm J: Alcohol consumption and inpatient health service utilization in a cohort of patients with alcohol dependence after 20 years of follow-up. Alcohol Alcohol 2017;52:227-233.

120 Rehm J, Roerecke M: Reduction of drinking in problem drinkers and all-cause mortality. Alcohol Alcohol 2013;48:509-513.

121 Pettinati HM, Gastfriend DR, Dong Q, Kranzler HR, O'Malley SS: Effect of extended-release naltrexone (XR-NTX) on quality of life in alcohol-dependent patients. Alcohol Clin Exp Res 2009;33:350-356.

122 Luquiens A, Reynaud M, Falissard B, Aubin $\mathrm{HJ}$ : Quality of life among alcohol-dependent patients: how satisfactory are the available instruments? A systematic review. Drug Alcohol Depend 2012;125:192-202.

123 François C, Rahhali N, Chalem Y, Sørensen P, Luquiens A, Aubin HJ: The effects of as-needed nalmefene on patient-reported outcomes and quality of life in relation to a reduction in alcohol consumption in alcohol-dependent patients. PLoS One 2015;10:e0129289.

124 Luquiens A, Whalley D, Crawford SR, Laramée P, Doward L, Price M, Hawken N, Dorey J, Owens L, Llorca PM, Falissard B, Aubin HJ: Development of the Alcohol Quality of Life Scale (AQoLS): a new patient-reported outcome measure to assess health-related quality of life in alcohol use disorder. Qual Life Res 2015;24:1471-1481. 